\title{
Exploration and Practice of Online Teaching During COVID-19 Period
}

\author{
Wu Xiujun ${ }^{1}$, Sun Xinyu ${ }^{2}$ \\ School of Mathematics and Computer Science, Jianghan University, Wuhan, Hubei, China \\ *Corresponding author. Email wxj1818@ sina.com
}

\begin{abstract}
During the novel coronavirus pneumonia outbreak, All college courses are taught Online which has given higher demands and challenges to the self-discipline, self-consciousness and initiative of students and the information literacy of teachers. This paper introduces the development of online teaching of postgraduate courses in our university, discusses various problems in teaching, and points out that the integration of online teaching and traditional teaching will become a trend in the 'post epidemic era'.
\end{abstract}

Keywords: Online teaching; live teaching; information literacy

\section{疫情期间线上教学的探索与实践}

\author{
吴秀君 ${ }^{1,}$ a 孙新宇 ${ }^{2,}$ b \\ 中国江汉大学, 数学与计算机科学学院, 武汉, 湖北 \\ awxj1818@sina.com \\ b389101584@qq.com
}

\section{摘要}

新一轮冠状病毒肺炎爆发期间, 高校课程都开展线上教学, 这对学生的自律性、自觉性、主动性和教 师的信息素养提出了更高的要求和挑战。介绍了我校研究生课程网络教学的发展情况, 探讨了网络教 学中存在的各种问题, 指出在“后流行时代”网络教学与传统教学相结合将成为一种趋势。

关键词: 线上教学; 直播教学; 信息素养

\section{1. 前言}

自从新冠病毒全球肆虐以来, 传统的线下教学不能 正常进行。2020 年 2 月 20 号, 高等教育司及时发布了 在新冠肺炎疫情防控期间支持高校在线教学的课程资 源平台和技术平台名单, 支持各高校积极开展 “停课不 停学, 停课不停教” [1,2,3]。各高校师生迅速响应, 一场 全国性的网上教学活动就这样应急展开。我校的 132 门 研究生课程全部开展了线上教学, 全部师生共同面对信 息技术支持下的线上教学挑战, 发现了不少问题, 也为 信息技术支撑下的教育和管理积累了经验。

\section{2. 线上教学的实施概况}

据统计, 我校疫情期间, 研究生网课形式主要有: 直播课、慕课、录播课、及时交流工具 ( $Q Q$, 微信, 钉 钉、网络课程平台等) 进行答疑与资料推送, 课程考核 主要采取在线考试 (由启明考试平台提供)、提交论文 或者推迟考试处理, 目前已有多门课程结课。

\section{3. 线上教学遇到的挑战}

我校作为一所地方性院校, 自 2012 年起已有老师 陆续在超星平台上建设慕课, 进行翻转课堂、spoc 等教 学改革, 因此由部分老师有网课经验, 但大部分老师之 前对网络教学也不陌生 ${ }^{[1,2,5]}$ 。开学之初学校对全校教师 开展了网络教学培训, 提供了校外访问接口、账户以及 免费开放的数据库、国家和企事业单位免费开放的网课 技术平台，供教师选择使用。教师遇到的第一个挑战就 是尽快熟悉各技术平台使用，并篮选出适合自己使用; 并从网络中挑选可以使用的课程资源如中国大学慕课 平台提供的课程, 供上课时结合使用。因为平台众多, 了解并使用对大部分主要采取传统课堂教学的老师还 是很费周章的。此外, 网络开放的慕课资源不一定完全 适合自己的学生, 因此, 教师要详细查看, 甄别来选择 并决定资源推送的时间、形式和内容等, 工作量也是非 常大。很多老师最终选取直播形式, 也是这个原因。最 终, $Q Q$ 直播、腾讯课堂、雨课堂、钉钉、腾讯会议比较 受青睐, 而直播课占到所有课程形式的 $75 \%$ 。在数学教 
育专业的必修课《数学思想与方法》上, 我们采取的教 学方案是课程 “ $Q Q$ 直播 $+Q Q$ 群交流” 为主和 “中国大学 MOOC” 为辅、“同步+异步” 混合的线上教学方案。该 方案基本满足了我们线上教学的需求, 保证了教学的有 序推进。

\section{4. 线上教学遇到的问题}

根据我们的教学实践, 线上教学中遇到的问题主要 来自四个方面: 1) 硬件和技术支持。直播中容易出现网 络卡顿、声音延迟、有回声、若学生没有全部静音则容 易出现杂音或被打扰现象；2）平台使用。在线上教学 初期不熟悉平台的功能和使用, 导致师生在直播界面管 理和交流的障碍；3）学生管理。在面对面的课堂教学 中, 老师很容易用眼睛巡视全场, 关注学生状态, 进行 及时的情感交流和互动, 而在 qq 直播教学中往往是分 享屏幕, 只闻其声不见其人, 师生要在另外的界面进行 文字交流, 来发现问题, 并了解学生的学习效果, 因此 需要适应这种多平台的切换。4)在线考试。在线考试往 往需要进行身份远程验证和视频监控, 试卷中的客观题 要线上作答和自动阅卷, 而主观题要写在纸上拍照上传, 另外为了防止作弊, 系统往往设置了开考五分钟后不能 进考场, 一旦退出后不能续考。在此过程中, 由于在线 考试平台大都是首次使用, 遇到了很多情况, 如刷脸登 录不进去, 系统故障导致超过登录许可, 登录进去有人 看不见试卷, 考试答案无法上传、因停电断网等意外退 出后不能继续作答或没有保存答案, 考试期间监控突然 黑频的责任认定，拍照上传的答案不够清晰等等。

疫情期间, 线上授课几乎在所有高校全面展开, 高 校教师的教学手段、教学方法和教学能力迅速得到提升, 研究生的学习方式和学习体验也随之更新 ${ }^{[1]}$ 。虽然短期 内教师面临全面网课带来的压力与挑战, 但这次的经验 也成为一笔宝贵的财富, 不仅积累了课程资源, 提升了 信息素养, 更为研究生将来的教学打开了新视角, 为未 来的线上教学与线下教学的融合打下了良好的基础。经 此一役, 各级产业资本也会聚焦平台的硬件投入和软件 升级, 改善用户体验, 积极应对线上教学的新要求, 客 观上提升了线上教学的未来成长空间。

\section{5. 线上教学的优势}

线上教学尽管还存在一些问题, 但也有线下教学不 可比拟的优势:

1）时空分离优势。

疫情期间, 线上教学的最大优势, 无疑是突破了传 统校内课堂面授的固定、封闭的时空局限, 给教师端和 学生端都带来了 “时空开放化” 的教学体验, 使教学过 程的各个环节从线下转移到线上, 在保证正常教学秩序 的同时, 也为新型教学方式和教学手段的应用带来了新 的启发。
2) 多工具优势。

依托智慧教学平台, 线上教学实现了平板电脑和手 机端、电脑端、教学管理系统端的即时沟通交流。线上 教学的授课形式是多元化的, 直播、录课、在线答疑等 可同时进行。

3）平台服务优势。

为保障师生疫情期间在家能够开展教学活动, 学校 提供给本校师生校外访问接口和账户以及免费开放的 数据库, 有知网研学平台、Web of Science、超星学 术资源、百度文库、万方数据库、重庆维普中文期刊服 务平台、人大复印报刊资料全文数据库、Spischolar 学术资源在线、CRS 核心论文、EPS 数据库 (信息服务 与数据分析平台)、海研全球科研项目数据库、北大法 意网 (法律资源库)、新东方多媒体学习库、起点考试 网 (考试资源库)、起点考研网、MET 全民英语、知识视 界 (科教视频资源库)、网上报告厅、畅想之星随书光 盘数据库、翼狐设计学习库、设计师之家等。另外还有 新冠病毒专题免费资源库, 如国家生物信息中心、万方 医学疫情专题、新型冠状病毒国家科技资源服务系统、 柳叶刀 (Lancet) 新型冠状病毒资源中心、Emerald 冠状 病毒及流行病管理相关专题等。

针对新型冠状病毒感染肺炎疫情对高校正常开学 和课堂教学造成的影响, 日前, 教育部印发《关于在疫 情防控期间做好普通高等学校在线教学组织与管理工 作的指导意见》, 并同步发布了一系列在线课程平台在 疫情防控期间支持高校在线教学服务方案信息。这些平 台主要有爱课程 (中国大学 MOOC), 学堂在线 (雨课堂 直播平台), 智慧树网、学银在线、超星尔雅网络通识 课平台、人卫慕课、优课联盟、好大学在线、融优学堂 (原北京高校优质课程研究会)、华文慕课、中国高校 外语慕课平台、高校邦、优学院、人民网公开课、智慧 职教、高校一体化教学平台、正保云课堂、浙江省高等 学校在线开放课程共享平台、安徽省网络课程学习中心 平台 (e 会学)、重庆高校在线开放课程平台、实验空间 - - 国家虚拟仿真实验教学项目共享平台、EduCoder 在线实践教学平台、北京大学讲座网、WE 外语智慧教育 平台、北京外国语大学外语在线学习平台。

这些平台提供的服务主要有：1、课程资源服务： 免费开放优质在线慕课课程资源供师生选用学习; 2、 在线教学服务: 学校专属在线学习空间一一 学校云服 务、优质慕课资源定制引用、智慧课堂、在线课课内直 播服务包括直播视频上传和板书功能、学生在线学习数 据服务, 视频监控下的在线考试和网上评分; 3、在线 直播讲座: 包括积极应对疫情、教学理论方法、在线 课程开发、混合式教学实践等模块; 4、教师在线培训 服务: 教师能力提升系列慕课课程; 5、疫情防治服务: 流行病学、传染病学通识类慕课和专业慕课在线课程资 源等。1、课程资源服务: 免费开放优质在线慕课课程 资源供师生选用学习; 2、在线教学服务: 学校专属在 线学习空间一一 学校云服务、优质慕课资源定制引用、 智慧课堂、在线课课内直播服务包括直播视频上传和板 书功能、学生在线学习数据服务, 视频监控下的在线考 
试和网上评分; 3、在线直播讲座: 包括积极应对疫情、 教学理论方法、在线课程开发、混合式教学实践等模 块; 4、教师在线培训服务: 教师能力提升系列慕课课 程; 5、疫情防治服务: 流行病学、传染病学通识类慕 课和专业慕课在线课程资源等。教师在教学平台可随时 对任教课程与班级进行个性化操作, 实现了课程建设与 学生管理的线上管理。

教师的直播课程、录播视频、教学资料都可供学生 随时随地反复查阅、播放、学习, 课程作业也可网上布 置、交流和批改。在线课程平台的大数据分析, 也为教 师掌握每个学生的学习进度、任务完成情况、作业正确 率提供了便捷条件, 教师可实时跟进每个学生的学习情 况, 对课程平台显示出学情预警的学生提供个别化的针 对性教学服务, 根据不同班级的实际及时调整教学设计 和教学策略, 科学引导学生进行有效的高质量学习。更 可贵的是, 平台服务使得教学过程实时跟踪, 学习痕迹 得以保留, 因此为教学评价提供客观依据, 使评价趋于 科学化、合理化和透明化。

4）线上教学资源共享优势和规模效应

线上教学为教育资源的开放和共享带来机遇, 使优 秀高校的课程资源受益于更多师生, 降低了低水平低质 量的重复建设, 解决了不发达地区教学资源紧缺的问题,
实现了跨区域跨校际资源共享，最大限度地保证了教学 资源配置的科学化和均衡化。

传统教育模式下, 教学规模与教学质量永远是一对 难以调和的矛盾。为注重学生的个体差异, 因材施教, 针对不同学生采用不同的教学方案, 注定班级规模不能 过大。线上教学可以多人同时进行规模化学习, 这是传 统课堂不可想象的。

\section{6. 教学案例}

以《数学思想与方法》的教学为例, 这是硕士专业学科 教学 (数学) 的必修课, 这门课的特点是理论与实践相 结合。根据教学大纲和课程要求, 制定教学目标, 细节 化教学环节。先查找公开慕课资源, 最终确定课堂教学 以直播形式为主、慕课资源自学为辅、定期资料推送加 QQ 群交流的教学形式, 作业是网上提交和批改, 实践环 节是讲课录像, 课程考核采取小论文的形式。从数学思 想方法的概念入手, 回顾数学思想方法的发展历程, 感 受数学思想方法的重要性。然后将主要数学思想根据其 特点和在学科中的地位和作业, 分专题制定教学实施方 案。

\section{表 1: 《数学思想方法》教学实施方案}

\begin{tabular}{|c|c|c|}
\hline 教学要求 & \multicolumn{2}{|c|}{$\begin{array}{l}\text { 1. 使学生建构起关于数学思想方法的认知结构, 认识数学思想方法的重要性, 增强数学思想方法教 } \\
\text { 学的自觉性, 提高实施数学思想方法教学的水平和能力。 } \\
\text { 2、通过 “数学思想方法的发展” 部分学习, 帮助学生了解数学思想方法的源头、几次重要突破和 } \\
\text { 现代数学的发展趋势, 并能正确理解数学的真理性, 确立动态的、拟经验主义的数学观。 } \\
\text { 3、通过 “数学思想方法例解” 案例学习, 使学员掌握数学教学中常用的数学思想方法及其应用, 。 } \\
\text { 4、通过 “数学思想方法教学” 部分学习和实践, 使学员掌握数学思想方法教学的特点, 并能将所 } \\
\text { 学数学思想方法初步应用于中小学数学教学。 }\end{array}$} \\
\hline 主要内容 & 教学实施 & 课后 \\
\hline 数学思想方法概述 & 自学中国大学慕课《数学思想与文化》中的数学思想章节 & 泛读: 推送资源 \\
\hline 公理化方法 & $\begin{array}{l}\text { 欧几里得公理体系在中学数学教学中极为重要。课下预习和课上直播 } \\
\text { 讨论的混合式教学模式 }\end{array}$ & 作业: 阅读心得 \\
\hline 符号思想 & 符号思想演化历史讲解+案例讨论+思想总结, 直播为主 & 作业:习题 \\
\hline $\begin{array}{l}\text { 模型思想 } \\
\text { 化归思想 } \\
\text { 集合分类思想 }\end{array}$ & $\begin{array}{l}\text { 教师直播+课上讨论+课下作业 } \\
\text { 学生讲课+师生评课+案例研讨 }\end{array}$ & 实践: 学生微课 \\
\hline 数形结合思想 & $\begin{array}{l}\text { 教学重点、师生共同讲解、讨论、改进、提高 } \\
\text { 混合式教学模式+观摩网上公开课+案例教学 }\end{array}$ & 学生: 数形结合思想小论文 \\
\hline 归纳思想 & $\begin{array}{l}\text { 自学电子书相关内容、结合中学实际写案例、总结一省高考某种数学 } \\
\text { 思想的考试题型、自学 }+q q \text { 群交流 }\end{array}$ & 学习: 推送资源并总结 \\
\hline 作业 & 课后习题、线上批改、及时反馈、随时交流、数据库资源可查阅、包 & 案例教学和讲课实习 \\
\hline \multirow{2}{*}{ 考核 } & 录制教学案例视频 & \multirow{2}{*}{ 结课 } \\
\hline & 小论文 & \\
\hline
\end{tabular}


表 2: 传统课堂模式与线上教学模式的比较

\begin{tabular}{|c|c|c|c|c|}
\hline 比较 & 传统课堂 & 特点 & 线上教学 & 特点 \\
\hline \multirow[t]{3}{*}{ 教学法 } & \multirow{3}{*}{$\begin{array}{l}\text { 组织教学 } \\
\text { 复习旧课 } \\
\text { 讲解新课 } \\
\text { 巩固新课 } \\
\text { 布置作业 }\end{array}$} & $\begin{array}{l}\text { 以教师为中心 } \\
\text { 以教材为中心 } \\
\text { 以课堂为中心 }\end{array}$ & \multirow{3}{*}{$\begin{array}{l}\text { 课前预习 } \\
\text { 课前自测 } \\
\text { 课上提问 } \\
\text { 师生讨论 } \\
\text { 知识总结 } \\
\text { 课下作业 } \\
\text { 网络互动 }\end{array}$} & \multirow[t]{2}{*}{$\begin{array}{l}\text { 以学生的学为中 } \\
\text { 心, 教师的中心 } \\
\text { 在于帮助学生的 } \\
\text { “学” }\end{array}$} \\
\hline & & \multirow{2}{*}{$\begin{array}{l}\text { 教师为主导 } \\
\text { 学生为主体 }\end{array}$} & & \\
\hline & & & & $\begin{array}{l}\text { 以学生为主体 } \\
\text { 教师是帮助者 }\end{array}$ \\
\hline 教学方式 & $\begin{array}{l}\text { 面对面授课 } \\
\text { 板书 } \\
\mathrm{ppt}\end{array}$ & $\begin{array}{l}\text { 直接语言交流, } \\
\text { 利于课堂上情感 } \\
\text { 表达, 但课后交 } \\
\text { 流少 }\end{array}$ & $\begin{array}{l}\text { 网络教学 } \\
\text { 慕课+课程资源 } \\
\text { 直播分享屏幕 } \\
\text { 课程录像回放 }\end{array}$ & $\begin{array}{l}\text { 非接触式交流, } \\
\text { 但可以随时网上 } \\
\text { 留言交流互动, } \\
\text { 以文字交流为主 }\end{array}$ \\
\hline 媒介 & $\begin{array}{l}\text { 教室 } \\
\text { 多媒体设施 }\end{array}$ & $\begin{array}{l}\text { 同一时间空间, } \\
\text { 不受外界限制 }\end{array}$ & $\begin{array}{l}\text { 直播平台 } \\
\text { 慕课平台 }\end{array}$ & $\begin{array}{l}\text { 受网络平台设置 } \\
\text { 和软硬件影响 }\end{array}$ \\
\hline 学习 & $\begin{array}{l}\text { 指定教室 } \\
\text { 和同学一起 }\end{array}$ & $\begin{array}{l}\text { 有老师现场管理 } \\
\text { 有同学陪伴 } \\
\text { 有学习气氛 } \\
\text { 但学习较被动, } \\
\text { 受时空限制 }\end{array}$ & $\begin{array}{l}\text { 虚拟空间 } \\
\text { 网络平台 }\end{array}$ & $\begin{array}{l}\text { 需要学生自主学 } \\
\text { 习、主动学习、 } \\
\text { 但不受时空限制 } \\
\text { 易受环境影响 } \\
\text { 产生孤独感 }\end{array}$ \\
\hline 评价 & 课堂考试 & $\begin{array}{l}\text { 基于结果的评价 } \\
\text { 易产生偏差 }\end{array}$ & $\begin{array}{l}\text { 线上考试+平台 } \\
\text { 学习数据跟踪 }\end{array}$ & $\begin{array}{l}\text { 基于过程的 评 } \\
\text { 价, 更科学 }\end{array}$ \\
\hline $\begin{array}{l}\text { 情感态度和价值 } \\
\text { 观 }\end{array}$ & $\begin{array}{l}\text { 被老师同学和班 } \\
\text { 级直接影响和塑 } \\
\text { 造 }\end{array}$ & $\begin{array}{l}\text { 利于建立关系、 } \\
\text { 宣泄情感 }\end{array}$ & 隔屏交流 & $\begin{array}{l}\text { 情感不易建立 } \\
\text { 态度价值观被影 } \\
\text { 响削弱 }\end{array}$ \\
\hline 结论 & \multicolumn{4}{|c|}{ 传统课堂与线上教学各有优劣, 后疫情时代要加强两者的融合 } \\
\hline
\end{tabular}

\section{7. 思考和展望}

由于线上教学于线下授课各有优缺点, 因此将两种 形式有效融合, 实现优势互补, 必将成为未来研究生教 学的主要方向。近年来, 在高校兴起的混合式教学改革、 如翻转课堂、Spoc+慕课、对分课堂都是线下授课与线 上课程资源整合的有效探索。互联网和人工智能技术加 快推动人才培养模式、教学方法改革, 这些技术将支撑 构建包含智能学习、交互式学习的新型教育体系, 学习 形态也随之发生重塑, 教师在备课模式、资源使用、内 容选择、测验练习、作业批改、考试、学生评价、个别 辅导等八个方面都将实现对信息技术的深度应用。

\section{REFERENCES}

[1] Qi Y.,L. An H. Undergraduate online teaching plan and its practice in epidemic period. Computer knowledge and technology. 2020,16(9):81-82

[2] Wu Y. Impact of novel coronavirus pneumonia on online teaching and coping strategies. Higher Education Forum. 2020,5
[3] Tan W. How to Conduct Knowledge Teaching Reform in the "Post-epidemic Era"? Educational information technology.2020,6

[4] Tyack D, Tobin W. The "grammar" of schooling: Why has it been so hard to change?. American Educational Research Journal Fall, 1994, (3):453-479.

[5] Cao Y. Thinking and Enlightenment of online teaching practice in epidemic period. Digital teaching in primary and secondary schools. 2020,6 